\title{
Three cases of alloimmune mediated pancytopenia in calves resembling bovine neonatal pancytopenia
}

\author{
L. Chantillon ${ }^{1 *} \mathbb{D}$, B. Devriendt² ${ }^{2}$ B. De Jonge ${ }^{3}$, J. Oostvogels ${ }^{4}$, J. Coppens ${ }^{1}$, M. L. Pas ${ }^{1}$, J. Bokma ${ }^{1}$ and B. Pardon ${ }^{1}$
}

\begin{abstract}
Background: Between 2007 and 2011 several thousands of calves died from bovine neonatal pancytopenia (BNP), a bleeding syndrome triggered by vaccine induced alloantibodies from the dams. Following withdrawal of the involved bovine viral diarrhoea virus (BVDv) vaccine, the incidence of this condition rapidly decreased, with no reported cases in the last 5 years. Here, we report a recent immune-mediated pancytopenia in three calves from two different suckler herds, clinically indistinguishable from BNP.

Case presentation: Three Belgian Blue suckler calves from two different farms, aged around two weeks, showed multiple bleedings disseminated on the skin and petechiae and ecchymoses on the mucosae. Blood examination confirmed anaemia, leukopenia and thrombocytopenia. BVDv infection was excluded. Despite blood transfusion and cortisone therapy, all three animals died. Necropsy and histology confirmed bone marrow depletion. Binding of lgG from the dams on leukocytes of the calves was demonstrated by flow cytometry. Two calves, originating from the same farm, received colostrum from the same dam. None of the calves were given colostrum replacers or colostrum supplements. No link with the BNP causing BVDV vaccine could be evidenced. However, dams had been vaccinated against bovine herpesvirus 1, parainfluenza-3 virus, bovine respiratory syncytial virus and bluetongue virus serotype 8 .
\end{abstract}

Conclusions: Alloimmune mediated pancytopenia was evidenced in three animals, clinically and pathologically indistinguishable from BNP. Whether this disease is again vaccine mediated remains to be determined.

Keywords: Vaccination- bleeding- immunopathology- thrombocytopenia- alloantibodies- Belgian blue calves

\section{Background}

Between 2007 and 2011, in Europe, and to a lesser extent in other continents, thousands of calves died due to the consequences of bovine neonatal pancytopenia (BNP) [1-11]. BNP is a bleeding disorder, typically developing between 10 and 21 days after birth, with severe internal and external bleeding (skin bleeding and petechia on mucosae) due to thrombocytopenia $[3,12]$. The clinical condition rapidly deteriorates and animals die either due

\footnotetext{
*Correspondence: laurens.chantillon@ugent.be

${ }^{1}$ Department of Large Animal Internal Medicine, Faculty of Veterinary Medicine, Ghent University, Salisburylaan 133, 9820 Merelbeke, Belgium Full list of author information is available at the end of the article
}

to haemorrhagic or septic shock [12]. The characteristic haematological finding is a pancytopenia starting with thrombocytopenia, followed by neutropenia, lymphopenia and non-regenerative anaemia [3, 9, 12-16]. At postmortem examination, consistently a complete depletion of the bone marrow from all cell populations is found [17-19]. BNP's clinical manifestation can range from hyperacute with high mortality to subclinical $[3,20]$. Variability in severity could be explained by differences in the quantity of ingested alloantibodies, genetics of dam, sire and calf and the lag time between birth and ingestion of colostrum $[18,21]$. The causal role of a bovine viral diarrhea virus vaccine (PregSure ${ }^{\circledR}$ BVD, Pfizer Animal Health, Berlin, Germany) in BNP was evidenced [2, 4, 
13, 22-26]. The adjuvanted vaccine induced the production of alloantibodies in some vaccinated cattle depending on their genotype of bovine major histocompatibility complex class I [2, 4, 21-25, 27-29]. Through pooling of colostrum or by the use of colostrum derivatives (colostrum supplements and replacers) multiple calves could be affected with the colostrum of one dam. The responsible vaccine was withdrawn from the market in 2010, and gradually the number of BNP cases declined to almost zero over a 5 -year period or in some regions even longer $[2,30,31]$.

Also before the emergence of BNP, bleeding disorders in calves occurred, albeit at low frequency. Multiple etiologies of these bleeding disorders have been described, like bacterial sepsis or viral (e.g. BVDv) infections, intoxications or hereditary diseases [12]. Reporting continues today, unfortunately often without a final diagnosis. To what extent immunological tests are nowadays routinely used in these sporadic cases of bleeding disorders is unknown to the authors. Here, we report three cases of alloantibody mediated pancytopenia in suckler calves, resembling BNP.

\section{Case presentation \\ Case history}

In August 2020, two female Belgian Blue calves were presented at the clinic of internal medicine in a critically ill state with complaints of skin bleeding. Case 1 and 2 were twelve and eight days old respectively and housed in the same stable with their mothers. The owner reported that the oldest calf started bleeding a few days earlier on skin of the ears, with trauma being the suspected cause. No fever was present. Treatment with gentamicin and penicillin by the herd veterinarian gave no clinical improvement. During the evening before admission, the clinical condition of case 1 deteriorated severely with development of dyspnoea. The owner noticed blood in the faeces, on the skin and petechiae and ecchymoses on oral and eye mucosae. Another calf started to show similar signs with skin bleeding, dyspnoea and also no fever. Both cases received one litre of a Hartmann-glucose $5 \%$ infusion from the veterinarian before referral to the clinic. Although they were born four days apart, both had received colostrum from the mother of case 1 . The case dam was born in 2013 and had received different vaccinations throughout the years. As a calf, she was intranasally vaccinated against respiratory syncytial virus (bRSV) and parainfluenza virus type 3 (PI-3) (Rispoval intranasal ${ }^{\circledR}$, Zoetis B.V., Capellen aan den Ijssel, The Netherlands) at about two weeks of age and then another vaccine against bRSV, Pi-3 and BVDv (Rispoval
$3^{\circledR}$, Zoetis Belgium SA, Louvain-la-Neuve, Belgium) at 3 and 4 months of age. Subsequently, she was vaccinated for bovine herpesvirus 1 with Bovilis IBR Marker Live $^{\circledR}$ (Intervet Nederland B.V., Boxmeer, The Netherlands) annually until 2018 and against bluetongue virus serotype 8 (BTV-8) with Bluevac BTV $^{\circledR}$ vaccine $(\mathrm{CZ}$ Veterinaria S.A., Porriño, Spain) annually until 2019. In 2020 , the bluetongue vaccine was changed and the dam received Bovilis Blue- $8^{\circledR}$ (Intervet International B.V., Boxmeer, The Netherlands). Also, since 2017, she was vaccinated annually against enterotoxigenic Escherichia coli, rotavirus and coronavirus with Rotavec ${ }^{\circledR}$ (Intervet International B.V., Boxmeer, Nederland). Before 2017, she was vaccinated annually for the same pathogens with Coroniffa ${ }^{\circledR}$ (Boehringer Ingelheim animal health France, Lyon, France). No problems were noticed during previous parturitions and also the mother of case 2 , born in 2017, delivered a healthy calf the year before. The two affected calves descent from different bulls.

The third case, a fourteen-day old male calf admitted in August 2021, had a similar clinical appearance. For five days he showed bloody faeces, bleeding on the skin of the ears and body, nose bleeding and petechiae on mucosae. The calf was still suckling and alert and no treatment was established before admission. $\mathrm{He}$ received colostrum from a dam other than his mother. The herd, which has no connection with the herd of case 1 and 2, had already been confronted with two bleeding calves in the past year, all of whom received colostrum from the same dam as case 3 . Both calves died from the bleeding disorder and were not admitted to the clinic. One of these calves was descended from the mother of case 3 although her first calf did not show any abnormalities or disease. Case 3 did not have the same sire as case 1 or 2 and sires of the two other affected calves in this herd could not be determined. The colostrum donating dam was born in March 2017 and received an intranasal vaccine against bRSV and PI-3 (Rispoval intranasal ${ }^{\circledR}$, Zoetis B.V., Capellen aan den Ijssel, The Netherlands) and an intramuscular vaccine against Mannheimia haemolytica (Pastobov $^{\circledR}$, Boehringer Ingelheim Animal Health Belgium SA, Brussels, Belgium) at one month of age. A booster with Pastobov ${ }^{\circledR}$ was injected a month later. Five and six months after birth, she had been vaccinated against bRSV, Pi-3 and BVDv (Rispoval $3^{\circledR}$, Zoetis Belgium SA, Louvain-la-Neuve, Belgium). Subsequently an annual vaccination against BVDv (Bovela ${ }^{\circledR}$, Boehringer Ingelheim Vetmedica $\mathrm{GmbH}$, Ingelheim/Rhein, Germany) and against BTV-8 (Bluevac BTV ${ }^{\circledR}, \mathrm{CZ}$ Veterinaria S.A., Porriño, Spain) was conducted. Since 2020 Bluevac $\mathrm{BTV}^{\circledR}$ was replaced by Bovilis Blue- ${ }^{\circledR}$ (Intervet International B.V., Boxmeer, The Netherlands). 


\section{Clinical examination}

On arrival at the clinic, a clinical examination of all three cases was carried out by the same clinician. Results can be consulted in Table 1. All three calves showed disseminated skin bleedings and multiple petechiae and ecchymoses on the mucosae of the mouth and eyes.

Ultrasonography was performed with a linear $7.5 \mathrm{MHz}$ probe (Easote $\mathrm{MyLab}^{\mathrm{TM}} 30$ Gold unit, the Netherlands) and $75 \%$ isopropanol solution (propanol-2, Chem Lab NV, Zedelgem, Belgium) as transducer agent between probe and skin. Case 1 and 2 showed some comet tails (B-lines) dispersed over the lung field and enlarged kidneys with a hypoechogenic medulla. Small intestines were immotile, but not dilatated. No other abnormalities were found. Case 3 showed B-lines at the cranial lung lobes. Small intestines were motile and the kidneys were normal. Only a mild omphaloarteritis was diagnosed.

\section{Blood examination}

After clinical examination, a blood-gas analysis and a full blood count of all three cases was conducted. All blood samples were taken from the jugular vein with a vacutainer system $\left(\right.$ Venoject ${ }^{\circledR}$, Terumo, Leuven, Belgium). Blood-gas analysis was performed on heparin blood tubes and analysed with RAPIDPoint ${ }^{\circledR} 405$ (Siemens Healthcare, Beersel, Belgium). Haematology was executed on standard ethylenediaminetetraacetic acid blood tubes with the IDEXX ProCyte Dx Hematology Analyzer $^{\circledR}$ (IDEXX Europe B.V., Hoofddorp, The Netherlands) and biochemistry on serum with the IDEXX Catalyst One Chemistry Analyser ${ }^{\circledR}$ (IDEXX Europe B.V., Hoofddorp, The Netherlands). The determination of the coagulation times in case 3 was done on a sodium citrate tube by an external laboratory. In Table 2 an overview of available blood parameters is given. Total bilirubin, total protein and gamma-glutamyltransferase were not measured in case 1 as the calf died shortly after arrival and only a limited amount of serum was collected.

Case 1 presented with severe metabolic acidosis, hypoglycaemia and hyperlactatemia. All three calves were severely leukopenic, thrombocytopenic and anaemic, confirming pancytopenia. Creatinine was increased, likely due to dehydration, and total protein was too low in case 2 and 3.

Sepsis couldn't be excluded, so blood was aseptically sampled for haemoculture. Two different aerobic BD BACTEC $^{\mathrm{TM}}$ blood culture media (Peds Plus ${ }^{\mathrm{TM}}$ and Plus Aerobic medium $^{\mathrm{TM}}, \mathrm{BD}$, Erembodegem, Belgium) were used in all three cases and in addition an anaerobic and a mycobacterium, yeast and fungi BD BACTEC ${ }^{\mathrm{TM}}$ blood culture (Lytic Anaerobic medium ${ }^{\mathrm{TM}}$ and Myco/F Lytic Culture Vials ${ }^{\mathrm{TM}}, \mathrm{BD}$, Erembodegem, Belgium) was used in case 3 . The blood cultures were subsequently incubated at $35^{\circ} \mathrm{C}$ in an automated system for the detection of microbial growth (BACTEC ${ }^{\mathrm{TM}} \mathrm{FX}$ ). After two days, two BD BACTEC $^{\mathrm{TM}}$ Peds Plus $^{\mathrm{TM}}$ and one BD BACTEC ${ }^{\mathrm{TM}}$ Plus Aerobic medium ${ }^{\mathrm{TM}}$ marked positive and were send to an external laboratory for identification and susceptibility testing by the disk diffusion method. Final identification was done by matrix assisted laser desorption/ionisation time-of-flight mass spectrometry (MALDI-TOF MS). Globicatella sanguinis was isolated from case 1, Staphylococcus chromogenes from case 2 and Staphylococcus xylosus and Sphingomonas paucimobilis from case 3. Except for Sphingomonas paucimobilis, all bacteria were multidrug resistant (MDR), defined as resistance to agents from at least three different antimicrobial classes [33] (data not shown). The Lytic Anaerobic medium ${ }^{\mathrm{TM}}$ and Myco/F Lytic Culture Vials ${ }^{\mathrm{TM}}$ blood cultures showed no growth and remained negative.

Table 1 Overview of the clinical examination of case 1, case 2 and case 3

\begin{tabular}{|c|c|c|c|}
\hline & Case 1 & Case 2 & Case 3 \\
\hline Body temperature $\left({ }^{\circ} \mathrm{C}\right)$ & 40.1 & 39.6 & 40.8 \\
\hline Pulse (bpm) & 100 & 80 & 140 \\
\hline Respiration rate (breaths/min) & 60 & 44 & 68 \\
\hline State & Lethargic & Alert & Alert \\
\hline Mucosae & Pale, moist & Pale pink & Pale \\
\hline Capillary refill time (s) & $>2$ & $>2$ & $<2$ \\
\hline Skin turgor & Reduced & Reduced & Reduced \\
\hline Vena jugularis & Slow filling & Slow filling & Normal filling \\
\hline Auscultation heart & Normal & Normal & Normal \\
\hline Auscultation lung & enhanced respiratory sounds & enhanced respiratory sounds & enhanced respiratory sounds \\
\hline Auscultation abdomen & Sloshing sounds & Sloshing sounds & Normal \\
\hline Faeces & Aqueous, melena, fresh blood & Aqueous, melena, fresh blood & Aqueous, melena, fresh blood \\
\hline Bodyweight & 57 & 60 & 56 \\
\hline
\end{tabular}


Table 2 Blood-gas analysis, full blood count and clinical chemistry of case 1, case 2 and case 3

\begin{tabular}{|c|c|c|c|c|}
\hline Parameter & Case 1 & Case 2 & Case 3 & Reference interval \\
\hline \multicolumn{5}{|l|}{ Blood-gas analysis ${ }^{\mathrm{a}}$} \\
\hline $\mathrm{pH}$ & 7.14 & 7.37 & 7.45 & $7.350-7.450$ \\
\hline $\mathrm{pCO}_{2}$ & 41.9 & 34.6 & 41.3 & $35-45 \mathrm{mmHg}$ \\
\hline $\mathrm{HCO}_{3}$ & 14.0 & 19.7 & 28.1 & $25-30 \mathrm{mmol} / \mathrm{L}$ \\
\hline Hematocrit & 11 & 15 & 12 & $25-35 \%$ \\
\hline Base excess & -13.4 & -5.1 & 3.8 & $-5-+5 \mathrm{meq} / \mathrm{L}$ \\
\hline Glucose & $<20$ & 76 & 79 & $60-80 \mathrm{mg} / \mathrm{dL}$ \\
\hline Lactate & 24.79 & 0.54 & 2.38 & $<2 \mathrm{mmol} / \mathrm{L}$ \\
\hline $\mathrm{Na}^{+}$ & 142.5 & 133.9 & 135 & $132-152 \mathrm{mmol} / \mathrm{L}$ \\
\hline $\mathrm{K}^{+}$ & 4.5 & 4.2 & 3.99 & $3.5-4 \mathrm{mmol} / \mathrm{L}$ \\
\hline $\mathrm{Ca}^{2+}$ & 1.14 & 1.2 & 1.16 & $1.0 \mathrm{mmol} / \mathrm{L}$ \\
\hline $\mathrm{Cl}^{-}$ & 99 & 103 & 99 & $100 \mathrm{mmol} / \mathrm{L}$ \\
\hline \multicolumn{5}{|l|}{ Complete blood count $^{\mathrm{b}}$} \\
\hline Red blood cell count & $2.00 \times 10^{12}$ & $3.32 \times 10^{12}$ & $2.82 \times 10^{12}$ & $4.47-9.35 \times 10^{12} / \mathrm{L}$ \\
\hline Hematocrit & 7.7 & 11.8 & 10.7 & $22.5-39.9 \%$ \\
\hline Hemoglobin & 2.9 & 4.9 & 3.7 & $7.4-12.8 \mathrm{~g} / \mathrm{dL}$ \\
\hline Mean corpuscular volume & 38.5 & 35.5 & 37.9 & $40.4-56.4 \mathrm{fL}$ \\
\hline Mean corpuscular hemoglobin & 14.5 & 14.8 & 13.1 & $11.5-18.5 \mathrm{pg}$ \\
\hline Mean corpuscular hemoglobin concentration & 37.7 & 41.5 & 34.6 & $30.2-33.5 \mathrm{~g} / \mathrm{dL}$ \\
\hline Red cell distribution width & 30.2 & 31.1 & 36.1 & $20.0-35.9$ \\
\hline \%Reticulocytes & $0.0 \%$ & $0.0 \%$ & 0.0 & \\
\hline Reticulocytes & 0.2 & 0.0 & 0.0 & $0.0-3.9 \mathrm{~K} / \mu \mathrm{L}$ \\
\hline White blood cell count & $0.36 \times 10^{9}$ & $0.17 \times 10^{9}$ & $0.97 \times 10^{9}$ & $2.71-17.76 \times 10^{9} / \mathrm{L}$ \\
\hline \%Neutrophils & $50.0 \%$ & $47.0 \%$ & $3.1 \%$ & \\
\hline \%Lymphocytes & $44.4 \%$ & $47.1 \%$ & $90.7 \%$ & \\
\hline \%onocytes & $2.8 \%$ & $0.0 \%$ & $6.2 \%$ & \\
\hline \%Eosinophils & $2.8 \%$ & $5.9 \%$ & $0.0 \%$ & \\
\hline \%Basophils & $0.0 \%$ & $0.0 \%$ & $0.0 \%$ & \\
\hline Neutrophils & $0.18 \times 10^{9}$ & $0.08 \times 10^{9}$ & $0.03 \times 10^{9}$ & $0.68-6.94 \times 10^{9} / \mathrm{L}$ \\
\hline Lymphocytes & $0.16 \times 10^{9}$ & $0.08 \times 10^{9}$ & $0.88 \times 10^{9}$ & $1.20-10.62 \times 10^{9} / \mathrm{L}$ \\
\hline Monocytes & $0.01 \times 10^{9}$ & $0.00 \times 10^{9}$ & $0.06 \times 10^{9}$ & $0.02-2.17 \times 10^{9} / \mathrm{L}$ \\
\hline Eosinophils & $0.01 \times 10^{9}$ & $0.01 \times 10^{9}$ & $0.00 \times 10^{9}$ & $0.01-1.23 \times 10^{9} / \mathrm{L}$ \\
\hline Basophils & $0.00 \times 10^{9}$ & $0.00 \times 10^{9}$ & $0.00 \times 10^{9}$ & $0.00-0.04 \times 10^{9} / \mathrm{L}$ \\
\hline Platelet count & 0 & 0 & 0 & $147-663 \mathrm{~K} / \mu \mathrm{L}$ \\
\hline Mean platelet count & 9.4 & 8.2 & 10.3 & $5.9-8.2 \mathrm{fL}$ \\
\hline Procalcitonin & $0.00 \%$ & 0.00 & 0.00 & $0.12-0.42 \%$ \\
\hline \multicolumn{5}{|l|}{ Biochemistry $^{b}$} \\
\hline Creatinine & 230 & 188 & 210 & $0-172 \mu \mathrm{mol} / \mathrm{L}$ \\
\hline Urea & 6.8 & 4.8 & 5.5 & $2.5-6.1 \mathrm{mmol} / \mathrm{L}$ \\
\hline Total bilirubin & Not available & $<2$ & $<2$ & $0-12 \mu \mathrm{mol} / \mathrm{l}$ \\
\hline GGT & Not available & 23 & 56 & 0-80IU/L \\
\hline Total protein & Not available & 33 & 44 & $58-80 \mathrm{G} / \mathrm{L}$ \\
\hline \multicolumn{5}{|l|}{ Coagulation indicators ${ }^{\complement}$} \\
\hline Prothrombin time & Not available & Not available & 49.1 & $24-36 s$ \\
\hline Activated partial thromboplastin time & Not available & Not available & 33.3 & $24-35 s$ \\
\hline Fibrinogen & Not available & Not available & 489 & $100-460 \mathrm{mg} / \mathrm{dL}$ \\
\hline D-dimer & Not available & Not available & 190 & $<500 \mathrm{ng} / \mathrm{mL}$ \\
\hline
\end{tabular}

a Reference values obtained from Dillane et al. (2018) [32]

${ }^{\mathrm{b}}$ Reference values obtained by the manufacturer

${ }^{\mathrm{C}}$ Reference values obtained by the extern laboratory 
All animals were ear notch tested for BVDv antigen by an indirect antigen-capture enzyme-linked immunosorbent assays (ELISA) (BVDv Ag/Serum Plus Test, IDEXX Laboratories, Inc., USA), as part of the Belgian BVDv eradication program. BVDv was not detected in any of the tested samples.

\section{Antibody binding assay}

The level of antibody binding was measured by flow cytometry. After disinfection of the skin, blood was drawn from the jugular vein with a vacutainer system (Venoject ${ }^{\circledR}$; Terumo, Leuven, Belgium) into a silica containing BD Vacutainer ${ }^{\circledR}$ SST $\mathrm{II}^{\mathrm{TM}}$ tube (BD, Erembodegem, Belgium). Calf leukocytes were isolated as previous described by Pardon et al. [19]. Upon isolation, cells were fixed in paraformaldehyde (4\%) and stained with sera of the dams (cases 1-3) and serum from a colostrum donor (case 3$)$. To this end, leukocytes $\left(1.0 \times 10^{5} / \mathrm{mL}\right)$ were transferred to wells of a conical bottomed 96-well microtiter plate. Cells were incubated $30 \mathrm{~min}$ on ice with two different serum samples diluted 1/50 in phosphate-buffered saline (PBS). As a control, leukocytes were stained with PBS only (control) or with bovine IgG at $0.2 \mathrm{mg} / \mathrm{ml}$ (case 3 ). Cells were then washed with PBS and stained with fluorescein isothiocyanate (FITC)-conjugated $F\left(a b^{\prime}\right) 2$ fragment of rabbit anti-bovine $\operatorname{IgG}(\mathrm{H} \& \mathrm{~L})$ (1/500 dilution, Tebu-bio nv, Boechout, Belgium). Upon incubating $30 \mathrm{~min}$ on ice, protected from light, cells were washed with PBS and analysed using a FACSAria III flow cytometer (BD Biosciences, Erembodegem, Belgium) or a cytoflex (Beckman Coulter, Brea, CA, USA) (case 3). Doublets were excluded and cells were selected based on their size
(FSC) and granularity (SSC). Data for at least 10.000 singlets were recorded using FACSDiva software (BD) or CytExpert (Beckman Coulter). Results from the flow cytometry, as shown in Figs. 1 and 2, revealed that the serum IgG from the dams binds to leukocytes isolated from their calves (case 1 and 2). Also for case 3 (Fig. 2), serum from the dam bound to leukocytes isolated from its calf, but not to leukocytes isolated from a healthy control calf. In addition, serum from the colostrum donor bound to the leukocytes isolated from case 3 as well as to the leukocytes isolated from the control calf.

\section{Therapy and case outcome}

Case 1 died shortly after arrival. Case 2 was critically ill and received intravenous antibiotic treatment with $5 \mathrm{mg} / \mathrm{kg} /$ day enrofloxacin (Floxadil $^{\circledR}$, Animalcare Ltd., York, United Kingdom) and $80.000 \mathrm{IE} / \mathrm{kg} / \mathrm{d}$ sodium benzylpenicilline (Penicilline 5.000.000 IE, Kela Pharma nv, Sint-Niklaas, Belgium). Also $0.6 \mathrm{mg} / \mathrm{kg}$ dexamethasonnatriumfosfaat (Rapidexon $2 \mathrm{mg} / \mathrm{ml}^{\circledR}$, Dechra Regulatory BV, Bladel, The Netherlands) was injected intramuscularly. The day after arrival, the haematocrit of the calf decreased even further to $10 \%$ and a blood transfusion was given. One litre of blood from an adult HolsteinFriesian cow, housed at the clinic, was transfused to the calf using $5.5 \mathrm{~g}$ of sodium citrate anhydrate (Natrii Citras ${ }^{\circledR}$, Fagron N.V., Waregem, Belgium) as anti-coagulant. The clinical condition improved slightly and treatment with enrofloxacine and natriumbenzylpenicilline was continued. After two days hospitalisation the animal's clinical condition deteriorated. Bronchopneumonia was diagnosed during the follow-up ultrasonographic
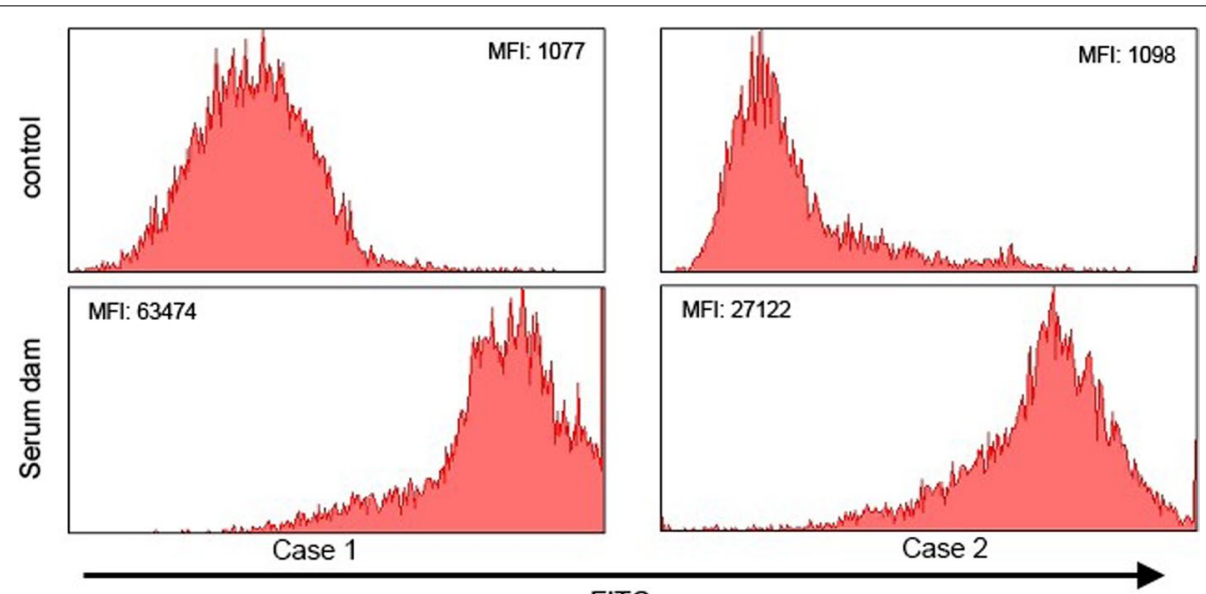

FITC

Fig. 1 Leukocytes from two calves (case 1 and 2) were stained with serum of their dams or PBS (control) and an FITC-conjugated anti-bovine IgG. The mean fluorescence intensities (MFI) of the leukocytes after incubation with the sera from both dams of case 1 (left) and case 2 (right) were compared with these following incubation with PBS. The MFI values, given in the histograms, of the sera from the cases were higher than those from both controls 

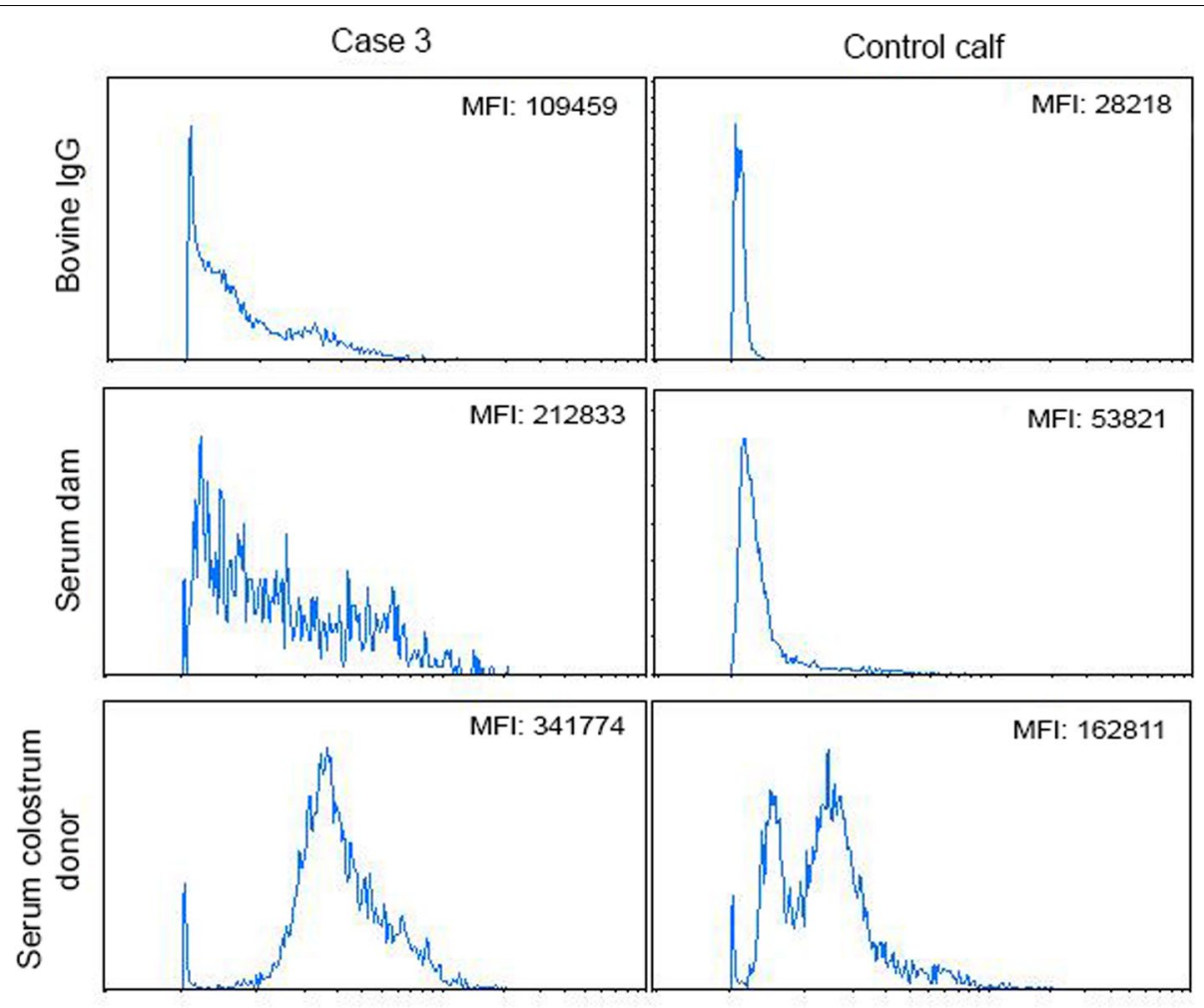

FITC

Fig. 2 Leukocytes from two calves (case 3 and a healthy control calf) were stained with serum from the dam of case 3 or a colostrum donor of case 3. As a control the leukocytes were stained with bovine lgG. Binding of bovine lgG to the cells was detected with an FITC-conjugated anti-bovine $\mathrm{lgG}$. The mean fluorescence intensities (MFI) of the leukocytes after incubation with the sera or bovine lgG are given in the histograms. MFI of PBS control staining: case 3: 101033; control calf: 27791

examination. Antibiotic treatment was revised and switched to $15 \mathrm{mg} / \mathrm{kg}$ spectinomycine-lincomycine (Emdactilin $150^{\circledR}$, Emdoka bv, Hoogstraten, Belgium) and the non-steroidal anti-inflammatory drug, $1.1 \mathrm{mg} /$ $\mathrm{kg}$ flunixini megluminum (Emdofluxin $50^{\circledR}$, Emdoka bv, Hoogstraten, Belgium) was given. The clinical condition further decreased and the calf died later that day. At admission, case 3 could still stand, but his general condition worsened soon after entry. A broad spectrum intravenous antibiotic treatment consisting of enrofloxacin and sodium benzylpenicilline was administered and a one litre blood transfusion was conducted. Very shortly after the blood transfusion, the calf deceased.

\section{Necropsy}

Necropsy was performed according to a standard protocol. All three calves were necropsied within $24 \mathrm{~h}$ after death. At gross examination, they had a pronounced anaemic appearance and displayed extensive generalized haemorrhages (petechiae and ecchymoses), shown in Fig. 3a. Haemorrhages in varying severity were present on the skin, mucosae, serosae (Fig. 3b) and muscles, but were most prominent at the subcutaneous peri-articular tissue and unilateral neck musculature in all three animals. The latter is most likely secondary to intramuscular injection(s). In case 2, a severe haemorrhagic bronchopneumonia and fibrinous pleuritis were present (Fig. 3b).

Histopathological examination of the lung, spleen, bone marrow, kidney and liver were performed for all three calves; the iliac lymph node was only sampled in case 1 and 3. Samples were fixed in 10\% neutral buffered formaldehyde and routinely processed. Histologically, the bone marrow was characterized by a total absence of hematopoietic tissue in case 1 (Fig. 4) and severe loss in case 2 and 3 . All cell populations were affected (total depletion). The spleen and lymph node displayed moderate (case 2 and 3 ) to severe (case 1) depletion of lymphoid cells of the periarteriolar lymphoid sheaths and lymph node cortex. Lung tissue of case 2 confirmed the gross diagnosis, the histological appearance was characterized by necrosuppurative bronchiolitis with intralesional growth of fungal hyphae in the bronchiolar and 


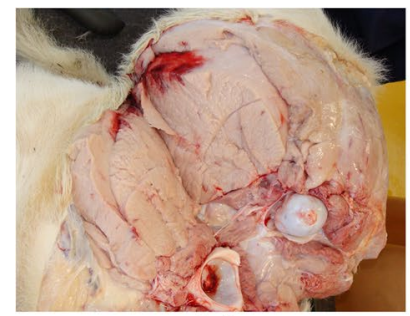

(a)

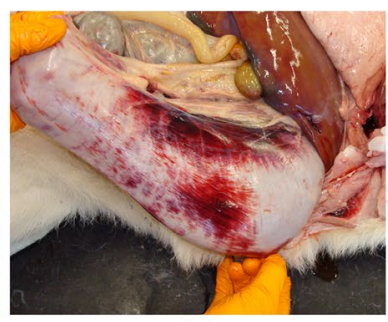

(b)

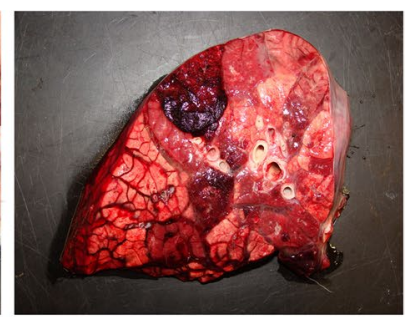

(c)

Fig. 3 Pictures taken during necropsy of case 1 and 2. a Case 1. Severe pallor of the hind limb musculature due to anaemia, with a focal intramuscular ecchymosis. b Case 1. Extensive serosal haemorrhage on the abomasum. c Case 2. Lung at cut surface. Haemorrhagic bronchopneumonia characterized by lobular, pink discoloration with haemorrhage and firm aspect upon palpation

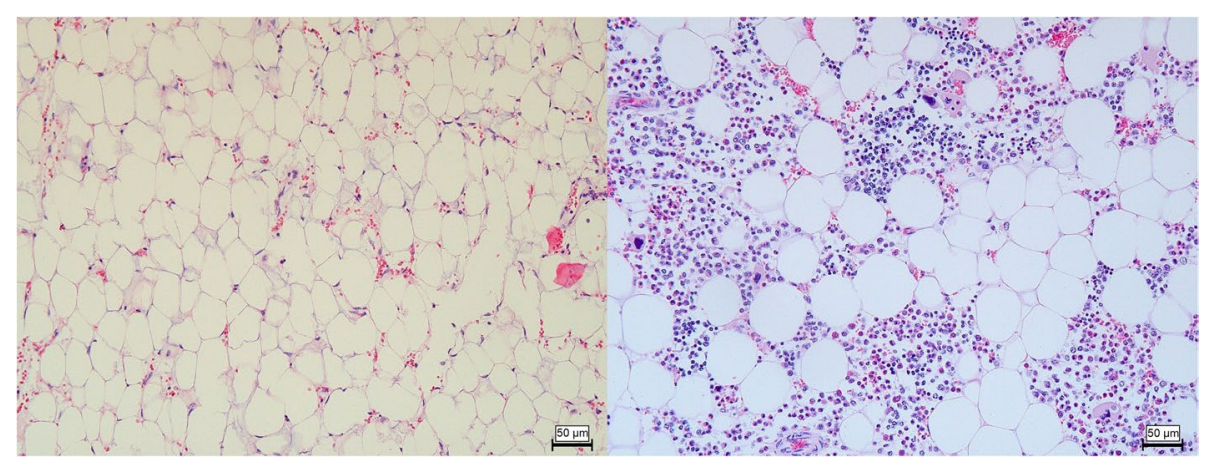

Fig. 4 Bone marrow of case 1 (left) and a control (right). There is complete depletion of haematopoietic cells in case 1. Hematoxylin and eosin stain, $20 x$

peribronchiolar tissue (Fig. 5). Also noticeable intraalveolar and interlobular haemorrhages and oedema were present with low numbers of neutrophils and macrophages.

\section{Discussion and conclusions}

This report describes three cases of pancytopenia in suckler calves, clinically indistinguishable from BNP. In the diagnostic work-up, known aetiologies were excluded. Thrombocytopenia is far more frequent as a cause of bleeding disorders in calves than pancytopenia, which fairly limited the differential list.

One of the most important differential diagnosis is BVDv. At birth, BVDv was tested by antigen-ELISA on ear notch as requested by the Belgian BVDv eradication program. This test reaches a sensitivity of 100\% (95\% CI: 90.50-100) [34]. The fact that the calf was not tested for BVDv at the peak of clinical signs, could be regarded as a limitation of this study. However, given that the farm of case 1 and 2 has been documented BVDv free since 2010 with regular monitoring, i.e. ear notch antigen ELISA of each newborn calf, makes involvement of BVDv very unlikely.
Bacteremia was evidenced in all calves. The presence of bacteria in the bloodstream can induce disseminated intravascular coagulation (DIC) [35]. An extensive DIC may cause thrombocytopenia and explain the increased bleeding tendency. As DIC involves systemic activation of the coagulation system and plasma levels of D-dimer increase by activation of the fibrinolytic system, the determination of D-dimers could have provided added value in case 1 and 2 and can be considered as a limitation in this report. In case 3, no increased values of D-dimers were observed. Although elevated D-dimer levels are not specific for DIC, levels are generally much higher than with other etiologies of clot formation [36, 37]. Also, primary pathogens such as Pasteurella multocida, renowned for haemorrhagic septicemia, could not be identified with blood culture [38, 39]. Given the extreme leukopenia, bacteremia is likely secondary, as previously seen in BNP calves [3]. The opportunistic nature of the isolated bacteria substantiates this. Nevertheless, the initial treatment of the ambulatory veterinarian in case 1 and 2, which could have eliminated a primary pathogen, cannot be neglected. In addition, the MDR bacteria isolated in these cases were resistant against penicillin with 


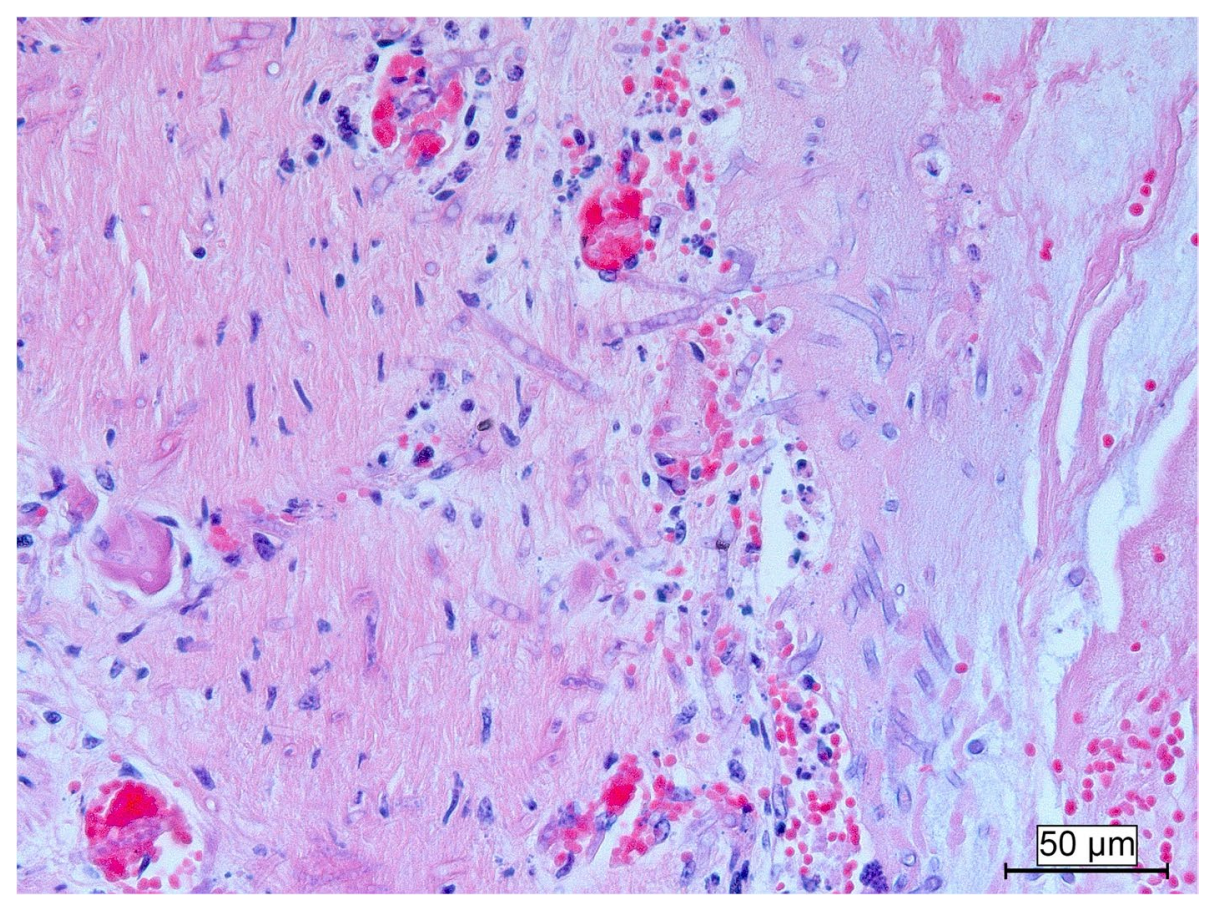

Fig. 5 Lung of case 2. Extensive invasive growth of fungal hyphae in the bronchiolar wall with only few inflammatory cells. Hematoxylin and eosin stain, 20x

disk diffusion testing. Disk diffusing for gentamicin was not done. The authors assume this was done since both bacteria were gram positive and natural resistance was suspected, yet aminoglycosides are known to have activity against certain Staphylococcus species [40, 41]. Next to this, the medium in the BD Bactec ${ }^{\mathrm{TM}}$ Peds Plus ${ }^{\mathrm{TM}}$ and Plus Aerobic medium ${ }^{\text {TM }}$ contains resins for antibiotic neutralization, which can give secondary pathogens, as isolated here, the opportunity to proliferate. We did not test for fungi by blood culture in case 1 and 2, but given that there was fungal pneumonia in one case, potentially also fungal sepsis occurred in these animals. Other known etiologies of bleeding disorders, like rodenticide poisoning [42] or hereditary diseases [43-45] are more associated with thrombocytopenia rather than pancytopenia. Also intoxication due to certain medication can be excluded in these cases simply due the fact that no medication was given before the onset of the clinical signs. There was also no mention of medication used during pregnancy except the vaccination.

By using flow cytometric assays, we evidenced binding of the alloimmune antibodies from the dam on leukocytes from the calves. Given the bone marrow depletion, it is likely that these antibodies also bind to precursors of the different cell lineages in the bone marrow, as was observed with BNP. In the past, the use of Pregsure ${ }^{\circledR}$ BVD was associated with BNP. In the last 10 years, this vaccine had not been used in the affected farm. An extensive enquiry exploring the use of colostrum or antibody supplements was performed in the last years, but none had been used on these farms. Mortality was high in the three described cases in this report, whereas the BNP cases occurring in the tail of the epidemic after removal of the vaccine had high survival chances $[3,46]$. This raises the suspicion that the animals in this case report were again confronted with a higher dose of alloantibodies.

Neonatal isoerythrolysis, an immune-mediated haemolytic anaemia, develops in neonatal animals following ingestion of colostrum containing antibodies against antigens on their erythrocytes. Hemolytic disease is described in cattle, however these cases were induced by vaccines against anaplasmosis and babesiosis which contained whole blood or erythrocyte membrane fragments [47]. To the author's knowledge, no cases have been published whereby hemolytic disease was induced by maternal synthetization with foetal red blood cells during previous parturitions, which is commonly described in horses [48]. Leakage of fetal erythrocytes during pregnancy is unlikely in cattle due to the cotyledonary epitheliochorial placenta which represents the least intimate association between maternal and fetal tissues. Also blood transfusions can induce maternal antibody production [49], but neither the mothers nor the colostrum donating dams received a 
blood transfusion during their lifetime which excludes a mismatched blood transfusion as an initiator. Next to this, no clinical signs of hemolysis such as icterus, hemoglobinemia or hemoglobinuria were seen in these cases. The observed anaemia can be explained by ongoing blood loss at the level of the many hemorrhages due to clothing failure.

Although no firm conclusions can be drawn from a single case report, vaccination as source of alloantibodies is an important hypothesis to explore. Both the Pregsure ${ }^{\circledR}$ BVD as the bluetongue vaccines use an adjuvant containing very potent saponins, in particular Quil A, of which some researchers believed to have contributed to the severity of BNP as it induced high and persistent alloantibody titers [17, 22]. In both herds, a lot of different vaccines were used. If we compare the vaccination strategies of both farms there are two vaccines that were used in both farms, namely a bluetongue vaccine and a vaccine against bRSV and PI-3. The two bluetongue vaccines, Bluevac $\mathrm{BTV}^{\circledR}$ and Bovilis Blue- $8^{\circledR}$, are the same vaccine and only differ from each other by name. However, it is not possible to draw any conclusions out of this preliminary information. As with BNP, a genetic component may also be involved in the pathology of the calves [18]. Involvement of the bull in these cases was not assessed in depth as the calves did not have a common sire and a further genetic determination was not within the scope of this case report. However, Belgian Blue is an intensively selected cattle population and as a consequence of the selection process in this breed the level of inbreeding is relatively high [50].

In conclusion, this report describes three cases of alloimmune mediated pancytopenia in suckler calves, resembling previous BNP cases. The immunoassay clearly demonstrates that the clinical conditions in these cases are immune-mediated through antibodies received from the dams via colostrum. Although an exact aetiology cannot be evidenced in a case report, taking the above reasoning into account, vaccine induced antibodies are among the more likely causes. It is worrisome that the case fatality rate was $100 \%$ in these three cases, which is reminiscent to the 2007-2010 outbreak of BNP. This report shows that increased surveillance and pharmacovigilance towards bleeding syndromes in calves is needed again.

\footnotetext{
Abbreviations

BVDv: Bovine viral diarrhoea virus; BNP: Bovine neonatal pancytopenia; BRSV: Bovine respiratory syncytial virus; PI-3: Para-influenza 3; MDR: Multi drug resistant; ELISA: Enzyme-linked immunosorbent assays; MALDI-TOF MS: Matrix assisted laser desorption/ionisation time-of-flight mass spectrometry; PBS: Phosphate-buffered saline; FITC: Fluorescein isothiocyanate; MFI: Mean fluorescence intensity; DIC: Disseminated intravascular coagulation.
}

\section{Acknowledgements}

We would like to thank Wouter van Mol his kind assistance writing this manuscript. Thanks also to the entire team of the Large Animal Internal Medicine for their valuable input.

\section{Authors' contributions}

LC wrote the manuscript and carried out clinical examinations, sampling and treatment. $\mathrm{BD}$ and $\mathrm{BDJ}$ contributed with their respective parts of the text. BD performed the flow cytometry assays and BDJ performed all three necropsies. $\mathrm{JO}$ did the initial clinical examinations and treatment at the farm before referral and provided information to write this report. JC, MP \& JB were research officers involved in investigation, diagnostics and treatment. They also helped writing the manuscript. BP drafted the main parts of the manuscript, contributed to discussions and substantively revised the draft manuscript. All authors read and approved the final manuscript.

\section{Funding}

This work was financed with own resources (Department of Large Animal Internal Medicine)

\section{Availability of data and materials}

The datasets used and/or analysed during the current study are available from the corresponding author on reasonable request.

\section{Declarations}

Ethics approval and consent to participate Not applicable.

\section{Consent for publication}

A written informed consent for publication of patient files and images and personal details was obtained from the farm owner.

\section{Competing interests}

The authors declare that they have no competing interests.

\section{Author details}

${ }^{1}$ Department of Large Animal Internal Medicine, Faculty of Veterinary Medicine, Ghent University, Salisburylaan 133, 9820 Merelbeke, Belgium. ${ }^{2}$ Laboratory for Immunology, Department of Virology, Parasitology and Immunology, Faculty of Veterinary Medicine, Ghent University, Salisburylaan 133, 9820 Merelbeke, Belgium. ${ }^{3}$ Department of Pathology, Bacteriology and Poultry Diseases, Faculty of Veterinary Medicine, Ghent University, Salisburylaan 133, 9820 Merelbeke, Belgium. ${ }^{4}$ Veterinary Practice Venhei, Geelsebaan 95-97, 2460 Kasterlee, Belgium.

Received: 30 August 2021 Accepted: 10 December 2021

Published online: 03 January 2022

\section{References}

1. Paul-Ehrlich-Institut. Scientists of the Paul-Ehrlich-Institut succeed in investigating the cause of bleeding calf syndrome. https://www.pei.de/ EN/newsroom/press-releases/year/2011/02-cause-bleeding-calf-syndr ome.html (2011). Accessed 08 Apr 2021.

2. Jones BA, Sauter-Louis C, Henning J, Stoll A, Nielen M, Van Schaik G, et al. Calf-level factors associated with bovine neonatal pancytopenia - a multicountry case-control study. PLoS One. 2013:8(12):e80619.

3. Pardon B, Steukers L, Dierick J, Ducatelle R, Saey V, Maes S, et al. Haemorrhagic diathesis in neonatal calves: an emerging syndrome in Europe. Transbound Emerg Dis. 2010;57(3):135-46.

4. Friedrich A, Büttner M, Rademacher G, Klee W, Weber BK, Müller M, et al. Ingestion of colostrum from specific cows induces bovine neonatal pancytopenia (BNP) in some calves. BMC Vet Res. 2011;7:10.

5. Holliman A, Caldow G. Case-control study on bleeding calf syndrome. Vet Rec. 2010;166(13):406.

6. Sánchez-Miguel C, McElroy M, Walsh E. Bovine neonatal pancytopenia in calves in Ireland. Vet Rec. 2010;166(21):664. 
7. Bednarski M, Houszka M, Hamala J, Nowaczyk R, Piasecki T. Hemorrhagic diathesis in neonatal calves - a case report. Medycyna Weterynaryjna. 2011;67:283-6.

8. Jaśkowski JM, Polak MP, Marszałek A, Nowak K, Frackowiak H, Olechnowicz J. Bovine neonatal pancytopenia in calves in Poland. Pol J Vet Sci. 2012;15(3):565-6.

9. Bell CR, Scott PR, Sargison ND, Wilson DJ, Morrison L, Howie F, et al. Idiopathic bovine neonatal pancytopenia in a Scottish beef herd. Vet Rec. 2010:167(24):938-40.

10. Corbière F, Foucras G, Lacroux C, Meyer G, Schelcher F. Haemorrhagic diathesis syndrome: clinical and epidemiological findings of 48 suspected cases in France, 2007-2009. In: Proceedings of the satellite symposium 'Haemorrhagic diathesis in calves', Europ buiatrics forum; 2009. p. 11-3.

11. ProMed-mail. Bovine Neonatal Pancytopenia (03): New Zealand. http:// www.promedmail.org (2011). Accessed 23 Mar 2021.

12. Friedrich A, Rademacher G, Weber BK, Kappe E, Carlin A, Assad A, et al. Gehäuftes Auftreten von Hämorrhagischer Diathese Infolge Knochenmarkschäcligung bei Jungen Kälbern. Tierarztl Umsch. 2009;64(10):423-31.

13. Lambton SL, Colloff AD, Smith RP, Caldow GL, Scholes SFE, Willoughby K, et al. Factors associated with bovine neonatal pancytopenia (bnp) in calves: a case-control study. PLoS One. 2012;7(5):5-11.

14. Buck $B$, Ulrich $R$, Kuiper $H$, Reinacher $M$, Peters $M$, Heimberg $P$, et al. Bovine neonatal pancytopenia in German Holstein calves. Berl Munch Tierarztl Wochenschr. 2011;124(7-8):329-36.

15. Kappe EC, Halami MY, Schade B, Alex M, Hoffmann D, Gangl A, et al. Bone marrow depletion with haemorrhagic diathesis in calves in Germany: characterization of the disease and preliminary investigations on its aetiology. Berl Munch Tierarztl Wochenschr. 2010;123(1-2):31-41.

16. Bridger PS, Bauerfeind R, Wenzel L, Bauer N, Menge C, Thiel HJ, et al. Detection of colostrum-derived alloantibodies in calves with bovine neonatal pancytopenia. Vet Immunol Immunopathol. 2011;141(1-2):1-10.

17. Bastian M, Holsteg M, Hanke-Robinson H, Duchow K, Cussler K. Bovine neonatal pancytopenia: is this alloimmune syndrome caused by vaccineinduced alloreactive antibodies? Vaccine. 2011;29(32):5267-75.

18. Deutskens F, Lamp B, Riedel CM, Wentz E, Lochnit G, Doll K, et al. Vaccineinduced antibodies linked to bovine neonatal pancytopenia (BNP) recognize cattle major histocompatibility complex class i (MHC I). Vet Res. 2011:42(1):1-10.

19. Pardon B, Stuyven E, Stuyvaert S, Hostens M, Dewulf J, Goddeeris BM, et al. Sera from dams of calves with bovine neonatal pancytopenia contain alloimmune antibodies directed against calf leukocytes. Vet Immunol Immunopathol. 2011:141(3-4):293-300.

20. Bell CR, Kerr MG, Scott PR, Ivan Morrison W, Brown H. Evidence of a high incidence of subclinically affected calves in a herd of cattle with fatal cases of bovine neonatal pancytopenia (BNP). BMC Vet Res. 2014;10(1):1-9.

21. Demasius W, Weikard R, Kromik A, Wolf C, Müller K, Kühn C. Bovine neonatal pancytopenia (BNP): novel insights into the incidence, vaccination-associated epidemiological factors and a potential genetic predisposition for clinical and subclinical cases. Res Vet Sci. 2014:96(3):537-42.

22. Kasonta R, Sauter-Louis C, Holsteg M, Duchow K, Cussler K, Bastian M. Effect of the vaccination scheme on PregSure ${ }^{\circledR}$ BVD induced alloreactivity and the incidence of bovine neonatal pancytopenia. Vaccine. 2012;30(47):6649-55.

23. Sauter-Louis C, Carlin A, Friedrich A, Assad A, Reichmann F, Rademacher $\mathrm{G}$, et al. Case control study to investigate risk factors for bovine neonatal pancytopenia (BNP) in young calves in southern Germany. Prev Vet Med. 2012;105(1-2):49-58.

24. Kasonta R, Holsteg M, Duchow K, Dekker JW, Cussler K, Bendall JG, et al. Colostrum from cows immunized with a vaccine associated with bovine neonatal pancytopenia contains Allo-antibodies that cross-react with human MHC-I molecules. PLoS One. 2014:9(10):e109239.

25. Kasonta R, Mauritz J, Spohr C, Sauter-Louis C, Duchow K, Cussler K, et al. Bovine neonatal pancytopenia-associated alloantibodies recognize individual bovine leukocyte antigen 1 alleles. Front Immunol. 2018;9(Aug):1-11.

26. Sauter-Louis $C$, Jones BA, Henning J, Stoll A, Nielen M, Van Schaik G, et al. Herd-level animal management factors associated with the occurrence of bovine neonatal pancytopenia in calves in a multicountry study. PLoS One. 2017;12(7):1-17.

27. Schröter P, Kuiper H, Holsteg M, Puff C, Haas L, Baumgärtner W, et al. Reproducibility of bovine neonatal pancytopenia (BNP) via the application of colostrum. Berl Munch Tierarztl Wochenschr. 2011;124(9-10):390-400
28. Benedictus L, Otten HG Van Schaik G, Van Ginkel WGJ, Heuven HCM, Nielen $\mathrm{M}$, et al. Bovine neonatal pancytopenia is a heritable trait of the dam rather than the calf and correlates with the magnitude of vaccine induced maternal alloantibodies not the MHC haplotype. Vet Res. 2014;45(1):1-13.

29. Krappmann K, Weikard R, Gerst S, Wolf C, Kühn C. A genetic predisposition for bovine neonatal pancytopenia is not due to mutations in coagulation factor XI. Vet J. 2011;190(2):225-9.

30. Benedictus L, Rutten VPMG, Koets AP. Pregnancy boosts vaccine-induced bovine neonatal pancytopenia-associated alloantibodies. Vaccine. 2016;34(8):1002-5.

31. Doll K. Bovine neonatal pancytopenia. In: World Buiatrics congress 3-8 June 2012 keynote lectures and round tables proceedings. Lisbon: Revista Portuguesa de Buiatria; 2012. p. 71-6.

32. Dillane P, Krump L, Kennedy A, Sayers RG, Sayers GP. Establishing blood gas ranges in healthy bovine neonates differentiated by age, sex, and breed type. J Dairy Sci. 2018;101 (4):3205-12

33. Sweeney MT, Lubbers BV, Schwarz S, Watts JL. Applying definitions for multidrug resistance, extensive drug resistance and pandrug resistance to clinically significant livestock and companion animal bacterial pathogens. J Antimicrob Chemother. 2018;73(6):1460-3.

34. Quinet C, Czaplicki G, Dion E, Dal Pozzo F, Kurz A, Saegerman C. First results in the use of bovine ear notch tag for bovine viral diarrhoea virus detection and genetic analysis. PLoS One. 2016;11(10):1-18.

35. Fecteau G, Smith BP, George LW. Septicemia and meningitis in the newborn calf. Vet Clin North Am - Food Anim Pract. 2009;25(1):195-208.

36. Levi M, Meijers JC. DIC: which laboratory test are most usefull. Blood Rev. 2011;25(1):33-7.

37. Toh $\mathrm{CH}$, Hoots WK. The scoring system of the scientific and standardisation committee on disseminated intravascular coagulation of the international society on thrombosis and Haemostasis: a 5-year overview. J Thromb Haemost. 2007;5(3):604-6.

38. Rhoades KR, Heddleston KL, Rebers PA. Experimental hemorrhagic septicemia: gross and microscopic lesions resulting from acute infections and from endotoxin administration. Can J Comp Med Vet Sci. 1967;31 (9):226-33.

39. Rimler RB. Coagglutination test for identification of Pasteurella multocida associated with hemorrhagic septicemia. J Clin Microbiol. 1978;8(2):214-8.

40. Krause KM, Serio AW, Kane TR, Connolly LE. Aminoglycosides : an overview. Cold Spring Harb Perspect Med. 2016;6(6):1-18.

41. Drew RH. Aminoglycosides. In: Cohen J, Opal M, Powderly WG, editors. Infectious diseases: Elsevier Ltd; 2010. p. 1373-81.

42. Valchev I, Binev R, Yordanova V, Nikolov Y. Anticoagulant rodenticide intoxication in animals - a review. Turk J Vet Anim Sci. 2008:32(4):237-43.

43. Meydan H, Yildiz MA, Özdil F, Gedik Y, Zbeyaz C. Identification of factor XI deficiency in Holstein cattle in Turkey. Acta Vet Scand. 2009;51(1):1-4.

44. Steficek BA, Thomas JS, Baker JC, Bell TG. Hemorrhagic diathesis associated with a hereditary platelet disorder in Simmental cattle. J Vet Diagn Investig. 1993;5(2):202-7.

45. Steficek BA, Thomas JS, McConnell MF, Bell TG. A primary platelet disorder of consaguineous Simmental cattle. Thromb Res. 1993;72(2):145-53.

46. Sauter-Louis CM, Staubach C, Reichmann F, Stoll A, Rademacher G, Cussler $\mathrm{K}$, et al. Spatial distribution and incidence of bovine neonatal pancytopenia in Bavaria, Germany. BMC Vet Res. 2020;16(1):1-12.

47. Tizard IR. Chapter 10 - adverse consequences of vaccination. In: Vaccines for veterinarians; 2021 . p. $115-30$.

48. MacLeay J. Neonatal isoerythrolysis. J of Eq Vet Sci. 2001;21(3):106-9.

49. Jalali SM, Ghorbanpour M, Razi Jalali M, et al. Occurrence and potential causative factors of immune-mediated hemolytic anemia in cattle and river buffaloes. Vet Res Forum. 2018;9(1):7-12.

50. Solé M, Gori AS, Faux P, et al. Age-based partitioning of individual genomic inbreeding levels in Belgian blue cattle. Genet Sel Evol. 2017;49(1):1-18.

\section{Publisher's Note}

Springer Nature remains neutral with regard to jurisdictional claims in published maps and institutional affiliations. 